\title{
Laparoscopic pyelolithotomy in the pelvic - dystopic kidney
}

\author{
Nariman Zhambayev, Ulanbek Zhanbyrbekuly, Yernur Ainayev, Gafur Khairli, \\ Ravil Sherkhanov, Ulan Zhaparov, Aleksey Sushchenko
}

Urology and Andrology Department, Astana Medical University, Astana, Republic of Kazakhstan

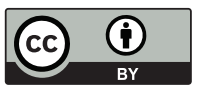

This work is licensed under a

Creative Commons Attribution 4.0

International License

Received: 2018-09-20

Accepted: 2018-10-15

UDC: 616.1

J Clin Med Kaz 2018; 3(49):46-49

Corresponding Author: Nariman Zhambayev, Urology and Andrology Department, Astana Medical University, Astana, Republic of Kazakhstan.

E-mail: Narik790@mail.ru

\section{Abstract}

Aim: Describe a clinical case and compare the difference in treatment methods at pelvic-dystopic kidney.

The article describes the clinical case of urolithiasis, in the pelvic - dystopic kidney. The stages of diagnosis and treatment reflected in the article testify to the present possibilities of modern medicine. Recovering the patient is the result of timely, skillfully chosen conservative and operational techniques.

Key words: laparoscopy, pyelolithotomy, pelvic kidney

\section{ЖАМБАС-ДИСТОПИРЛЕНГЕН БУЙРЕКТЕГІ ЛАПАРОСКОПИЯЛЫҚ ПИЕЛОЛИТОТОМИЯ}

Жамбаев Н.Н., Жанбырбекулы У., Айнаев Е.И., Хайрли Г.З., Шерханов Р.Т., Жапаров У.С., Сущенко А.Ф.

Урология және андрология бөлімі, Астана медициналық университеті, Астана, Қазақстан Республикасы

\section{ТҰЖЫРЫМДАМА}

Мақсаты: Клиникалық жағдайды сипаттау және дистопирленген бүйрек астауы тасы кезінде емдеудің түрлі әдістерін салыстыру.

Мақалада жамбас-дистопирленген бүйректің, несеп-тастың клиникалық жағдайы баяндалған. Мақалада баяндалған диагностика және емдеудің кезеңдері қазіргі медицинаның бүгінгі мүмкіндіктері туралы куәландырады. Пациенттің сауығуы - қазіргі замаңғы, тәжірибелі таңдалған консервативті және жедел әдістердің нәтижесі.

Негізгі сөздер: лапароскопия, пиелолитотомия, жамбас бүйрегі

\section{ЛАПАРОСКОПИЧЕСКАЯ ПИЕЛОЛИТОТОМИЯ В ТАЗОВО - ДИСТОПИРОВАННОЙ ПОЧКИ}

Жамбаев Н.Н., Жанбырбекулы У., Айнаев Е.И., Хайрли Г.З., Шерханов Р.Т., Жапаров У.С., Сущенко А.Ф.

Отделение урологии и андрологии, Медицинский университет Астана, Астана, Республика Казахстан

\section{PЕЗЮME}

Цель: Описать клинический случай и сравнить различие методов лечения при камнях лоханки дистопированной почки.

В статье изложен клинический случай мочекаменная болезнь, тазово-дистопированной почки. Отраженные в статье этапы диагностики и лечения свидетельствуют о настоящих возможностях современной медицины. Выздоровление пациента - результат своевременных, квалифицированно выбранных консервативных и оперативных методик.

Ключевые слова: лапароскопия, пиелолитотомия, тазовая почка 


\section{Введение}

Наиболее распространенными видами врожденных пороков развития являются аномалии развития почек и верхних мочевых путей и составляют от 12,9 до $40 \%$ всех врожденных пороков и обнаруживаются у 3-5,5 \% от общего количества урологических больных. Дистопия почки является аномалией развития мочевой системы и относится к аномалиям расположения органа. Различают следующие аномалии расположения: торакальная, поясничная, подвздошная и тазовая. Клинически аномалия расположения почки может никак не проявляться. Клиническая картина может присоединиться при нарушении гемо- и уродинамики. Также вследствие атипичного расположения, может частично нарушаться почечная функция. Клиническая урология относит дистопию почки к врожденным почечным аномалиям [1]. Дистопия развивается в результате задержки перемещения и ротации почки из тазовой области в поясничную в процессе эмбриогенеза. Первоначальная закладка почки у эмбриона происходит в малом тазу, по мере развития происходит перемещение в краниальном направлении и к моменту рождения, почки занимают свое нормальное анатомическое положение в поясничной области на уровне XI-XII грудного - I-III поясничных позвонков по обе стороны от позвоночного столба. Воздействие неблагоприятных факторов при беременности может привести к нарушению миграции и ротации почки; в этом случае новорожденный рождается с аномальной топографией почек или дистопией. Вследствие атипичного расположения, аномальной васкуляризации, лечение камней в эктопических тазовых почках представляет проблему для урологов [2]. Развитие малоинвазивных техник, таких как чрескожная нефролитотомия, лапароскопическая пиелолитотомия, роботизированная лапароскопическая пиелолитотомия и ударно-волновая литотрипсия, способствовало эффективному, безопасному удалению камней из аномально расположенной почки [3]. Однако хирургические доступы к мочевым камням в аномальных почках до сих пор являются сложной задачей. В современных клинических руководствах по мочекаменной болезни, до сих пор нет четкого предложения о предпочтительных методах лечения относительно удаления камней в таких почках. Напротив, рекомендации по терапии камней в нормальных почках четко обозначены в клинических рекомендациях Европейской Ассоциации Урологов (ЕАУ). В нашей публикации мы хотим продемонстрировать клинический случай: камня лоханки дистопированной почки удаленного путем лапароскопической пиелолитотомии.

\section{История болезни}

Ниже представлен клинический случай из практики урологического отделения ГКП на ПХВ «Городской больницы №1» города Астаны.

Пациентка Т., 57 лет, поступила в отделение урологии с жалобами на боли в поясничной области слева, общую слабость. Считает себя больной в течение длительного времени. Страдает длительное время мочекаменной болезнью, хроническим калькулезным пиелонефритом. Находилась на стационарном лечении в отделении урологии, проведено обследование и оперативное лечение. В апреле месяце2018г.-стентированиелевогомочеточника.Пациентке при госпитализации было выполнено ультразвуковое исследование брюшной полости, заключение -камень в лоханке левой почки. Гидронефроз слева. Тазовая дистопия левой почки. Компьютерная томография абдоминального сегмента, заключение - КТ картина тазовой дистопии левой почки. Конкремент левой почки. Гиперплазия тела левого надпочечника. Двухсторонний хронический пиелонефрит. Хронический холецистит. Ультразвуковое исследование брюшной полости и неконтрастная абдоминальная компьютерная томография подтвердили диагноз. С учетом результатов исследований, больному установлен диагноз: Мочекаменная болезнь. Камень левой почки. Аномалия развития верхних мочевых путей. Тазовая дистопия левой почки. Хронический калькулезный пиелонефрит, в стадии неполной ремиссии.

КТкартина-леваяпочкарасположенапаравертебрально на уровне L5-S1 позвонков, незначительно ротирована кпереди. Чашечно - лоханочная система почек умеренно расширена, не деформирована. В лоханке левой почки визуализируется конкремент, размерами около 2,7х3,2 см, плотностью до 290 - 310едН. Левый мочеточник имеет извитой ход.

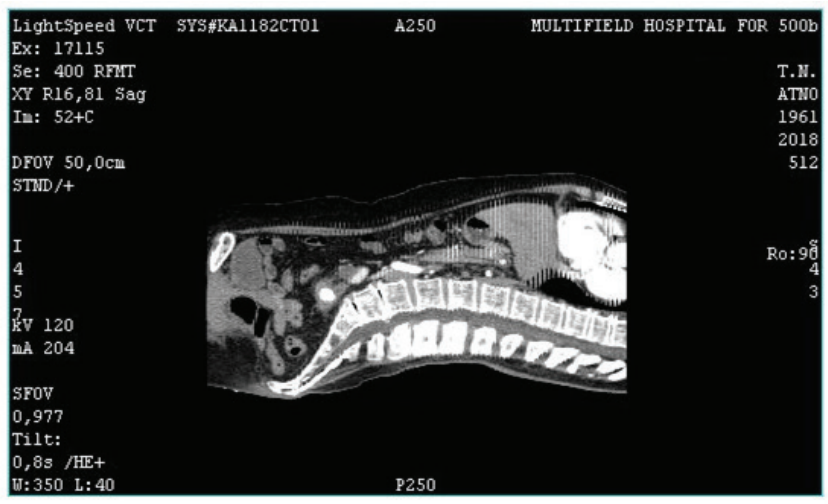

Рисунок 1

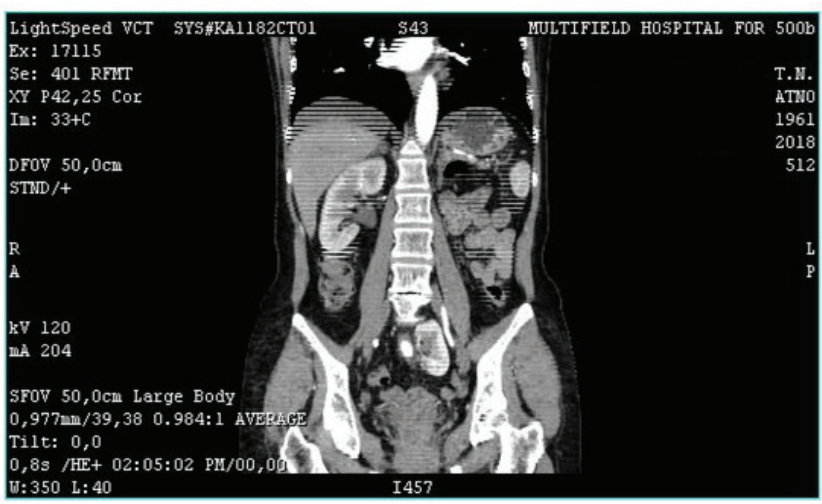

Рисунок 2

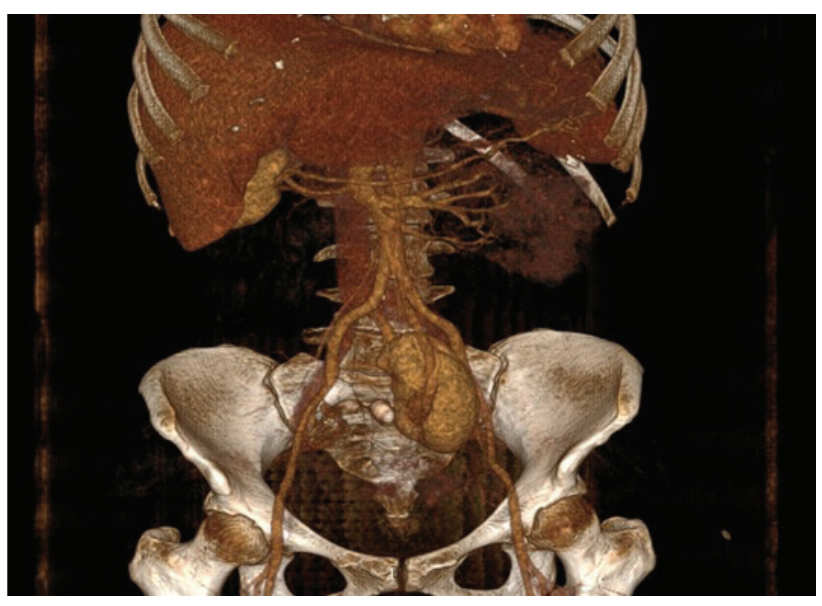

Рисунок 3 


\section{Методы}

После укладки больной в положении Тренделенбурга, операционное поле обработано спиртом. После инсуфляции углекислого газа в брюшную полость введены 4 троакара (2-№10, 2-№5). Произведена ревизия органов брюшной полости: патологических образований нет. Мобилизована сигмовидная кишка. Вскрыта париетальная брюшина в левой подвздошной области, где определяется верхний полюс, средний сегмент почки. Выделена лоханка, где определяется выпячивание, предположительно место стояния конкремента. Произведена пиелотомия, выделилась светлая моча, визуализируется конкремент светло коричневого цвета, с помощью диссектора конкремент извлечен и удален; В мочевой пузырь введен цистоскоп №20Ch., в левое устье установлен почечный стент №5, до 17 см беспрепятственно. Лоханка ушита непрерывно. Через троакарное отверстие в брюшную полость установлен раневой дренаж. Раневой дренаж удален на 6-е сутки, Стент удален через 1 месяц.

\section{Обсуждение}

Наш клинический случай аналогичен по срокам госпитализации и длительности операции предыдущим случаям лапароскопической пиелолитотомии при нормально расположенной почке. Наш случай соответствует данным ранее опубликованным в исследовании Chang T.D (Таблица 1) [4]. Оперативное время составляло в среднем 2-5 часов с использованием 3- или 4-портового хода, и всем пациентам устанавливался дренаж перед закрытием. Следует отметить, что троим из девяти пациентов потребовался переход на конверсию. Несмотря на это, авторы пришли к выводу, что лапароскопическая пиелолитотомия в эктопической почке имеет значение в ситуации, когда ударно-волновая литотрипсия или ПНЛТ не выполнимы. В исследовании Ergin G. et al [5] в котором производилось сравнение эффективности различных методов лечения камней эктопированных почек, авторы пришли к выводу

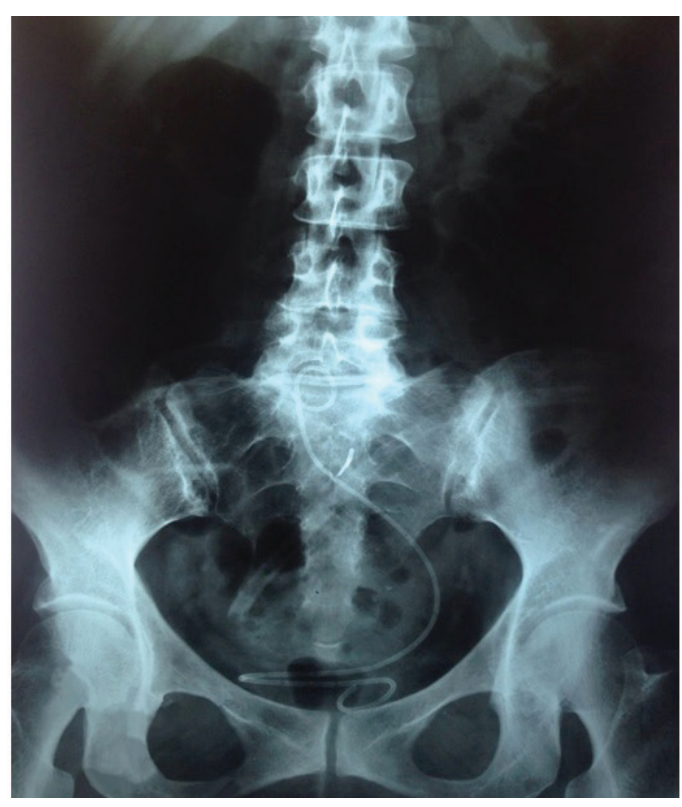

Рисунок 4 - Обзорная урограмма - стент левой почки.

что «ретроградная интраренальная хирургия» (РИРХ) и лапароскопическая пиелолитотомия являются наиболее эффективнымиметодамилечения.ПрисопоставленииРИРХи лапароскопической пиелолитотомии была отмечена большая безопасность и меньшая инвазивность первого метода, и авторы рекомендовали использовать его как метод первого выбора при камнях среднего и мелкого размера. Вследствие высокой стоимости и хрупкости гибкого уретерореноскопа во многих урологических клиниках отсутствует данный вид оборудования для выполнения РИРХ. Следовательно, в тех случаях когда выполнение РИРХ невозможно первой линией терапии при камнях эктопированной почки является лапароскопическая пиелолитотомия. Также преимуществом лапароскопического метода, является $100 \%$ степень очистки почки от камня, так как производится удаление конкремента целиком, без фрагментации.

Таблица 1 Сравнение лапароскопической пиелолитотомии и ПНЛТ для камней в области почек $>1,5$ - 2cм [4].

\begin{tabular}{|c|c|c|c|}
\hline Процедура & $\begin{array}{l}\text { Лапароскопическая пиелолито- } \\
\text { томия }\end{array}$ & ПНЛТ & ДЛТ \\
\hline Обезболивание: & общее & общее & MAC \\
\hline Количество портов доступа & $3-4$ & 1 & нет \\
\hline Доступ & Транс или забрюшинный & забрюшинный & нет \\
\hline Хирургическое время: & От 2 до 5 часов & От 1 до 3 часов & От 1 до 3 часов \\
\hline Дренирование: & Стент (1 неделя) & Нефростома (от 2 до 7 дней) & стент (1 неделя) \\
\hline Нахождение в больнице: & 1-2 дня & От 3 до 5 дней & 0-2 дня \\
\hline Степень очистки почки от камня: & $100 \%$ & $95 \%$ & $52-78 \%$ \\
\hline Дополнительные процедуры (\%): & $27 \%$ конверсия в открытые & $1-2(12-90 \%)$ & $1-2(50-60 \%)$ \\
\hline Переливание крови: & $0 \%$ & $2-10 \%$ & $<1 \%$ \\
\hline Количество пациентов: & 11 (9 эктопических) & 494 & $>2700$ \\
\hline
\end{tabular}

*MAC = контролируемая анестезия, ПНЛТ = перкутанная нефролитотрипсия 
Преимуществами лапароскопического подхода является более короткое пребывание в больнице и низкий процент послеоперационных осложнений по сравнению с открытыми оперативными вмешательствами [6]. Риск повреждения окружающих абдоминальных органов и сосудов делает открытую операцию также как и ПНЛТ при эктопированной почке сложной задачей. Лапароскопический способ позволяет избежать открытой операции и ассоциируется с меньшей травматичностью и обеспечивает дополнительную безопасность [7]. Чисто лапароскопический доступ менее инвазивен, чем открытый доступ, но из-за технических сложностей удлиняется операционное время. Применение роботизированной лапароскопии с использованием системы da Vinci позволяет усовершенствовать лапароскопическую технику и улучшить результаты лечения [8]. Однако вследствие дороговизны роботизированной системы внедрение данной техники ограничено. В клиническом исследовании Rana et al. [9] описывается опыт применения метода ПНЛТ у 48 пациентов для удаления камней из почек при аномалиях развития. Полной степени очистки почки от камней удалось достичь у $81 \%$ больных, остальным пациентам потребовалось проведение повторной процедуры "Second look” и процедуры дистанционной литотрипсии, в конечном итоге степень очистки почки составила 96\%. Таким образом, лапароскопическая пиелолитотомия обладающая более высокой степенью очистки почки от камней является более предпочтительным методом лечения.

\section{Результаты}

Лапароскопическая пиелолитотомия была успешно выполнена в тазово-дистопированной почке с оперативным временем 150 минут. Послеоперационный период протекал без особенностей, проводилась профилактика инфекционных осложнений. Раневой дренаж удалили после УЗИ контроля на шестые сутки. Больная выписана на десятый день после операции в удовлетворительном состоянии.

\section{Выводы}

Для пациентов с большим камнем в почечной лоханке эктопической почки лапароскопическая пиелолитотомия обеспечивает безопасный и эффективный подход. Минимальная инвазивность доступа обеспечивает скорейшую активизацию и реабилитацию больных.

Disclosures: There is no conflict of interest for all authors.

Patient informed consent: obtained

\section{Список литературы}

1. Esghi AM, Roth JS, Smith AD. Percutaneous transperitoneal approach to a pelvic kidney for endourological removal of a staghorn calculus. J Urol. 1985;134:525. [PubMed]

2. Toth C, Holman E, Pasztor I, Khan AM. Laparoscopically controlled and assisted percutaneous transperitoneal nephrolithotomy in a pelvic dystopic kidney. J Endourol. 1993;7:303. [PubMed]

3. Harmon WJ, Kleer E, Segura JW. Laparoscopic pyelolithotomy for calculus removal in a pelvic kidney. J Urol. 1996;155:2019. [PubMed]

4. Chang TD, Dretler SP. Laparoscopic pyelolithotomy in an ectopic kidney. J Urol. 1996;156:1753.[PubMed]

5. Ergin G, Kirac M, Unsal A, Kopru B, Yordam M, Biri H. Surgical management of urinary stones with abnormal kidney anatomy. Kaohsiung J Med Sci. 2017 Apr;33:207-11.

6. Gaur DD, Agarwal DK, Purohit KC. Retroperitoneal laparoscopic Gil-Vernet pyelolithotomy: an initial report. Min Inv Ther. 1994;3:55

7. Gupta NP, Yadav R, Singh A. Laparoscopic transmesocolic pyelolithotomy in an ectopic pelvic kidney. JSLS. 2007;11(2):258260 [PMC freearticle] [PubMed]

8. Nayyar R, Singh P, Gupta NP. Robot-assisted laparoscopic pyeloplasty with stone removal in an ectopic pelvic kidney. JSLS. 2010;14(1):130-132 [PMC freearticle] [PubMed]

9. Rana A. M., Bhojwani J. P. Percutaneous nephrolithotomy in renal anomalies of fusion, ectopia, rotation, hypoplasia, and pelvicalyceal aberration: uniformity in heterogeneity // J. Endourol. - 2009; - Vol. 23 (4): 609-614.

How to cite this article: Nariman Zhambayev, Ulanbek Zhanbyrbekuly, Yernur Ainayev, Gafur Khairli, Ravil Sherkhanov, Ulan Zhaparov, Aleksey Sushchenko. Laparoscopic pyelolithotomy in the pelvic - dystopic kidney [in Russian]. J Clin Med Kaz. 2018; 3(49):46-49 